\title{
Mental incapacity and restraint for treatment: present law and proposals for reform
}

Andrew M Bridgman University of Manchester, Manchester

\begin{abstract}
The House of Lords in Fv West Berkshire Health Authority [1989] considered the lawfulness of providing care and treatment for a mentally incapacitated adult. They did not, however, directly consider the use of restraint to enable the provision of care in the face of resistance from the patient. The law has since had good cause to give consideration to this important issue. This paper establishes the present law in the context of using restraint to deliver care. Although the legal principles established have derived from what might be considered to be "hard cases", life-and-death cases, they apply to all aspects of routine medical, dental and nursing care. Further, the paper considers the recent government proposals and the effect those proposals may have on the routine care of such patients.

(Fournal of Medical Ethics 2000;26:387-392)
\end{abstract}

Keywords: Law; mental incapacity - adults; statutory restraint; common law restraint

\section{Introduction}

The combination of demographic trends and changes in care philosophy means that many patients with mental disability live within the community. Formerly such patients may have been cared for in psychiatric hospitals or other institutions that would have also provided routine health care. The reduction in the number of institutionalised patients means that they, or at least their carers, are turning to the general medical and dental services, and the community services for their routine medical and dental care. Such patients will present the doctor, dentist, practitioner nurse or health visitor with a variety of perplexing and complex problems. Perhaps the most difficult question that stems from the mental disability will be the patient's capability of participating in treatment decisions. Most especially when their response to proposed treatment, refusal or resistance, suggests that their decision making capacity appears to be impaired.

In normal circumstances when there is conflict between the health care worker's recommendations and treatment proposals and the patient's wishes, questions of competency do not arise. However, when dealing with patients with mental disability such conflict will usually give rise to some concern about the patient's decisional capacity and the treatment of patients with a history of mental disability can raise serious ethical issues. Gillon identifies the possible conflict between the principles of helping those who are in need of help and also of recognising their right to make their own decisions. ${ }^{1}$ He suggests that the polar cases are uncontroversial. The fully competent patient who rejects treatment whatever the consequences ought to have that decision respected, and with the exception of treatment for mental illness ${ }^{2}$ the law supports that view. The patient who is clearly incompetent and unable to make a decision ought to have that decision made for him or her. The House of Lords in $F v$ West Berkshire $H A^{3}$ empowered the health care professional as the decision maker.

The effect, however, of any mental disability on cognitive function is not necessarily an "all or nothing" phenomenon. The patient's ability to make decisions about care interventions may not be affected. Such a situation might be further complicated if the patient were to remain noncommunicative. Is the patient's behaviour a manifestation of his or her true judgment or of his or her illness or arrested development? The patient may be compliant and cooperative. Is cooperation to be interpreted as indicative of agreement with treatment proposals? Has this patient consented or made no decision at all? Conversely, the patient may physically resist all attempts at treatment, despite being in obvious discomfort. Is this patient making a decision to forgo treatment that ought to be respected? Is it a refusal of treatment or no decision at all? The potential exists, if behaviour is misinterpreted, for depriving the patient of his autonomy or depriving the patient of treatment that he requires.

Thus when faced with a patient who appears to be refusing treatment considered to be beneficial, the health care professional will first have to decide whether or not the patient is making a choice that ought to be respected.

\section{Assessment of competence}

This assessment is not only a decision of considerable ethical sensitivity but one of considerable importance in view of the legal consequences that may follow. The assessment of competence is not, however, the subject of this paper and a review of the law and proposals for reform have been dealt 
with in an earlier issue of this journal. ${ }^{4}$ If the patient is deemed competent the provision of treatment against his wishes would be unlawful, "as constituting the crime of battery or the tort of trespass". If the patient is incompetent $F v$ West Berkshire also established a legal duty of care towards incompetent patients. "In many cases ... it will not only be lawful for doctors, on the ground of necessity, to operate on or give other medical treatment to adult patients disabled from giving their consent: it will also be their common law duty to do so." 6

Thus failure to provide care, despite resistance, may result in liability for negligence, a view endorsed in $\operatorname{Re} T$ : "The surgeon will be liable in damages if he fails to operate in accordance with the principle of necessity when there was no valid decision by the patient"?

\section{Treatment in the face of resistance}

A health care professional faced with an incompetent patient resisting treatment is then left with the real problem of delivery of care. If an examination or treatment is considered to be in the patient's best interests then the law says that it would be lawful notwithstanding the lack of consent or the apparent refusal, and failure to deliver may be a failing of duty. The patient's resistance or combativeness may require the use of some form of restraint to enable safe and effective delivery of care. The lawfulness of the use of restraint was not considered in $F v$ West Berkshire, although it may have been implicit, ${ }^{8}$ and it was some seven years before the courts considered the issue.

\section{The lawfulness of restraint}

"It is a legal wrong to use constraint on an adult beyond what it is authorised by statute or ancient common law powers connected with crime and the like."

This judgment implies that the use of restraint against any adult is unlawful, unless permitted by application of the law. This may be so even when the adult is consenting to the restraint. In A-G's reference (no 6 of 1980) ${ }^{10}$ it was held that a person's consent is irrelevant, with notable exceptions, and cannot prevent criminal liability for an offence if actual bodily harm was intended. Although one of the notable exceptions alluded to was reasonable surgical intervention, for which restraint may be necessary, it is important to know whether restraint to enable treatment of a mentally incompetent adult patient is authorised by the law.

\section{Statutory authority for restraint}

For detained patients under the Mental Health Act 1983, section 63 provides that: "The consent of the patient shall not be required for any medical treatment given to him for the mental disorder from which he is suffering, ...."

Two important conditions are attached to this section. First, that medical treatment includes nursing care, and care, habilitation and rehabilitation under medical supervision (section 145(1)).
Second, that the medical treatment given must be for the mental disorder from which the patient is suffering. The act does not give any powers to impose treatment for any physical disorders which are unrelated to the patient's mental disorder. However, the causal link between physical and mental disorder has allowed the courts to utilise this section and declare that some treatments (including reasonable restraint) would be lawful despite the patient's refusal. The justification is that some physical disorders may be symptomatic of, or may contribute to the severity of, or be the cause of, some mental disorders. Treating the physical disorder is in effect treating the mental disorder. Section 63 has been stretched to include within its scope, forced feeding for the treatment of anorexia and the delivery of a baby via a caesarean section.

In Riverside Mental Health NHS Trust $v$ Fox,${ }^{11}$ the first case explicitly to authorise the use of either physical or pharmacological restraint, the judge hearing the application (ex parte) had no difficulty concluding that feeding of a detained anorexic patient was treatment within section 145 of the act and declared that: "forced feeding ... is medical treatment for her mental disorder under the provisions of section $63 \ldots{ }^{\prime \prime} 12$

However, the order was discharged on appeal, for reasons of procedure. It was not long until the opportunity arose again to consider this issue. In $R e$ $K B$ (adult) (mental patient:medical treatment) it was considered that: "relieving symptoms is just as much a part of treatment as relieving the underlying cause" 13 and authorised the forced feeding of an anorectic patient. The use of section 63 in such a way is understandable when treating an illness such as anorexia, recognised within medicine as a "mental illness". The link between the illness and the symptoms is clear and such a view later received support from the Court of Appeal who considered that there was: “ ... no conceptual vagueness about treating the symptoms or consequences of a mental disorder" but who recognised that "naturally there will be borderline cases". ${ }^{14}$

In Tameside and Glossop Acute Services Trust v CH an application was made to the court to authorise the performance of a caesarean section on a detained patient, using restraint if necessary. The obstetrician considered that without induction of birth and perhaps the performance of a caesarean section the child would die in utero. It was the opinion of the consultant psychiatrist that the birth of a stillborn child would have a profound deleterious effect on the patient's mental health; that the delivery of a healthy baby would help recovery from the psychosis; and that the anti-psychotic medication interrupted by the pregnancy could be resumed. On the basis of these opinions it was not: " ... stretching language unduly to say that achievement of a successful outcome of her pregnancy is a necessary part of the overall treatment of her mental disorder" 15 and, " ... since the defendant's consent to it is not required, Dr G is entitled, should he deem it clinically necessary, to use 
restraint to the extent to which it may be reasonably required in order to achieve the delivery.....”16

This line of argument is not without limit. In $B v$ Croydon Health Authority the Court of Appeal was keen to emphasise the distinction between treatment for physical symptoms of mental disorder and treatment for entirely unconnected physical disease: "The case of $\operatorname{Re} C$... in which a schizophrenic was held entitled to refuse treatment for gangrene, is distinguishable. The gangrene was entirely unconnected with the mental disorder" ${ }^{4}{ }^{14}$

Even with that distinction so clearly noted it may be possible to interpret section 63 to cover many other ailments. Patients detained under the act are as likely as any other person to suffer from acute or chronic painful conditions-toothache, for example. There is evidence to show that acute or chronic pain can in fact exacerbate psychological distress. ${ }^{17}$ If the co-morbidity of pain and the mental illness could be demonstrated, then treatment without the consent of the patient, including the use of restraint, might be justified under section 63, provided that relief of symptoms would enhance the patient's mental condition, or increase the chances of successful treatment for his mental condition.

\section{Restraint at common law}

The general concern of this paper is the care of patients living within the community. Section 63 is unlikely to provide the authority required by the law. For such patients, and also for the majority of detained patients, the use of restraint to enable treatment would need authority from the common law. Prior to Tameside there was no common law decision expressly authorising the use of restraint in order to facilitate treatment of incapacitated patients. Although Tameside provided an opportunity for a declaration of the lawfulness of restraint at common law, $(\mathrm{CH}$ was thought to be incompetent and the treatment was clearly in her best interests) the judge took refuge in statute and a common law declaration was left for another day.

The first declaration of the lawfulness of the use of restraint arose from two cases concerning the performance of caesarean sections. In contrast to the Tameside case the physical health of the mothers rather than their mental health was at risk. Two applications were made, within half-an-hour, to the High Court in respect of the performance of caesarean sections on two mothers refusing treatment, despite substantial risk to their own health and that of their unborn children. ${ }^{18}$ Discounting the risk of harm to the unborn children, ${ }^{19}$ Johnson J declared that both lacked the mental competence to make a decision and that as performance of the caesarean sections would be in their best interests, performance in the absence of consent would not be unlawful. Full judgment was given in Norfolk and Norwich when Johnson J also took the opportunity to declare that: "... in circumstances such as the present the court does have the power at common law to authorise the use of reasonable force". ${ }^{20}$
Johnson J did not declare that the use of reasonable force would not be unlawful as a necessary adjunct to any treatment that was being provided in the best interests of the patient. He declared that the court had the power to authorise the use of reasonable force. This is in contrast to $F v$ West Berkshire where the House of Lords declared that any treatment that was provided in the best interests of a patient disabled from giving consent would be lawful, and that the authority of the court would not be required save in special circumstances. ${ }^{21}$

Statute does not envisage applications to be made in every case where restraint or the use of reasonable force is at issue-only where there is doubt. It is suggested that this would also be the view of the court at common law. ${ }^{22}$ In $\operatorname{Re} M B$ Butler-Sloss LJ suggests that following a decision that the patient is not competent to refuse treatment then: "such treatment may have to be given against her continued objection if it is in her best interests that the treatment be given despite those objections. The extent of force or compulsion which may become necessary can only be judged in each individual case and by the health professionals. It may become for them a balance between continuing treatment which is forcibly opposed and deciding not to continue with it.",23

\section{A matter of clinical judgment?}

If it were necessary for applications to be made to the court in every instance where restraint was anticipated, not only would the judicial system become overwhelmed, but the provision of medical, dental and other routine care for "special needs patients" would grind to a halt. It is submitted that so long as the criterion of reasonableness is satisfied then the use of restraint or force would be lawful in order to facilitate treatment.

\section{Reasonable restraint or force}

The provision of care in the face of resistance from the patient is impossible without controlling the patient's behaviour in some way. The patient's behaviour can be controlled physically or it may be necessary to subdue the patient's behaviour with sedative drugs or through the use of general anaesthesia. Restraint, therefore, can be considered as chemical or pharmacological, or simply the use of physical force. Whichever means is employed it needs to be reasonable, but how is reasonableness to be determined?

$F v$ West Berkshire determined that the treatment of a patient disabled from giving consent would be lawful if the treatment was in the patient's best interests, whether or not the treatment is in the patient's best interests being tested by "accepted medical practice". In determining reasonableness with regard to the use of restraint none of the cases make any direct reference to the test that will be applied. Norfolk and Norwich applies the principle of necessity: "I seek to apply the principle enunciated by Lord Goff in $R e F$, namely that there must be a necessity to act and: 'the action taken 
must be such as a reasonable person would in all the circumstances take, acting in the best interests of the assisted person"". ${ }^{24}$

This seems to imply that whether or not the method of restraint or the force employed was reasonable would be determined by reference to "accepted medical practice" - the Bolam test. ${ }^{25}$ Provided that a doctor, dentist, nurse (or carer?) was working in accordance with practices adopted by others working in the field of "special needs" then the treatment of a patient incapable of giving consent would be lawful-including the use of restraint.

There is however, reason to be wary of the certainty of such authority, not so much in respect of the treatment carried out, but, in respect of the means employed to enable its provision. The test of a "reasonable person" acting in the best interests of the patient imports into trespass principles from the tort of negligence. In ordinary negligence cases the court might apply a risk or cost/benefit analysis to the facts in determining an objective standard of car $^{26}$; Bolitho $v$ City and Hackney $H A$ reaffirmed the long held view ${ }^{27}$ that the courts are not bound by professionally determined standards unless that opinion can be demonstrated to be reasonable or responsible. ${ }^{28}$

In assessing whether or not in a particular situation the use of restraint or the method employed was reasonable the courts may turn to other areas of the law. In her book Mental Health Law ${ }^{29}$ Brenda Hoggett suggests that whether the means of restraint is considered to be reasonable will be subject to the same two tests as those imposed by the Criminal Law Act 1967 for the use of reasonable force in the prevention of a crime. ${ }^{30}$ The first proposition is that the force must not be excessive. It must be no more than is necessary to control the patient's behaviour and allow the proposed procedure to be carried out successfully. A patient who offers minimal resistance could be examined, treated or fed with minimal physical force such as an assistant holding her hand, or using light oral sedation. If this patient's head or arms were restrained to prevent any movement, or if the patient was given a general anaesthetic, then even though other professionals might employ such methods the courts might consider them unreasonable.

Second, the degree of force used or the method of restraint employed must be in proportion to the expected benefits of successful completion of treatment. Most interventions are made on the basis that there will be a net benefit for the patient. The provision of dental care for mentally incompetent adults illustrates this requirement well. The extraction of a painful or infected tooth carries the immediate high risk of discomfort and swelling, the lower risk of post-operative infection and the extremely low risk of severe bone infection. Nevertheless, such extractions are carried out on the basis that the prospect of harm from treatment is outweighed by the expected benefit. Quite often dental treatments are carried out in the absence of symptoms, in order to prevent problems from occurring in the future. The decision to intervene in these situations is based on the probability and magnitude of the problems that might arise should the treatment not be provided.

When faced with a mentally incompetent patient who is clearly suffering or who needs treatment to prevent deterioration (including an examination) and the development of future discomfort and sepsis, and refuses help, the dentist may wish to override that refusal. The law has in effect made the dentist the proxy decision maker and in consideration of enabling treatment, the degree of force used or method of restraint employed is to be made in consideration of the expected net benefit. It is one thing to remove an obviously painful abscessed tooth under general anaesthesia, perhaps using a degree of physical force, with its attendant risks of morbidity and mortality, it is another to use general anaesthesia to carry out nothing more than a routine inspection. In order to satisfy this aspect of the "reasonableness" test the dentist will need to consider on balance the likelihood of immediate or long term harm to the patient, either physical or psychological, that might result from the enforced intervention against the measure of harm that might arise from failure to deliver the care. In the eyes of the law this is a matter of clinical judgment.

\section{Proposals for statutory reform}

Common law authority exists for the use of some form of restraint, provided that because of the mental disability the person is unable to make a decision for himself and the treatment (including the use of restraint) would be in his best interests. For the most part that is a satisfactory situation but much responsibility falls upon the health care professional in his role as the patient's proxy. The issue of competence is clearly crucial to the decision to act for a patient who is unable to decide for himself or herself. At present the legal responsibility for making an assessment of the patient's decisional capacity and all that follows lies with the attending health care professional.

On 27th October 1999 the government outlined its proposals for legislative reform relating to the adult without capacity: Making Decisions. ${ }^{31}$ However, these proposals form no part of the legislative timetable for the present parliamentary session. The process began in 1991 leading to a Law Commission report, Mental Incapacity, ${ }^{32}$ and the consultation paper, Who Decides..$^{33}$ Making Decisions aims to clarify the law to afford greater protection for those who are unable to make decisions for themselves and for those who care for them. The matter of assessing capacity and deciding best interests recommended by the Law Commission has already been fully discussed in this journal ${ }^{4}$ and as Making Decisions largely follows those recommendations no further discussion is necessary.

The government proposes to introduce legislation that will provide a general authority for those acting or taking decisions for the benefit of persons without capacity. Although not defined it seems 
likely that there should be a general authority "to do anything for the personal welfare or health care of a person who is, or is reasonably believed to be, without capacity in relation to the matter in question if it is in all the circumstances reasonable for it to be done by the person who does it" ${ }^{34}$ and "reasonably believed by the decision maker to be in the person without capacity's best interests". ${ }^{35}$ The suggested examples are, paying bills, giving medication and providing help with dressing or feeding. It is clear that the rationale of the general authority is to regulate day-to-day decisions. ${ }^{36}$ Will the general authority extend to such "humdrum matters as routine medical and dental care"? ${ }^{37} \mathrm{Or}$ does the general authority only relate to general/ nursing care rather than health care interventions? Perhaps that will become clear with the code of practice to be published in association with the legislation.

Making Decisions accepts recommendations to extend the powers of attorney to include decision making on health care, subject to reservations, ${ }^{38}$ most notably that the patient must be reasonably believed to be without capacity. Therefore, in view of the fact that Making Decisions accepts that incapacity is a specific concept and recommends the "functional approach" 39 it seems that the health care professional's duty to assess the patient's decisional capacity remains.

Making Decisions proposes a single court jurisdiction which will deal with aspects relating to adults without capacity. ${ }^{40}$ The court will have powers to make health care decisions or appoint a manager to do so on its behalf. The government view is, however, that decisions of the court are preferable to an appointment; most health care decisions are one-off decisions and better made by the court.

A number of issues concerning health care raised by the Law Commission and discussed at length in Who Decides? are not discussed in Making Decisions. These include advance statements and those interventions which it has previously been suggested should require court approval or other independen supervision. Presumably these "treatments", which cannot be considered curative or prophylactic such as sterilisation, organ donation, abortion, genetic screening and research, will still require the approval of the court.

Most of the government's proposals for legislation will assist the provider of care and protect the interests of the patient. However, in contrast to the present common law situation, Making Decisions accepts the Law Commission's recommendation that the general authority to act should not extend to "the use or threat of force to enforce the doing of anything to which that [assisted] person objects... . This provision is not to preclude the taking of steps which are necessary to avert a substantial risk of harm to the person concerned". ${ }^{41}$ The Law Commission report (no 231) defines "harm" to include: " ...the impairment of, or an avoidable deterioration in, physical or mental health" ${ }^{42}$ Notwithstanding that this is a definition relating to public law protection, in the absence of any other definition in Making Decisions (because it does not purport to advance public law protection for people at risk) it must now be interpreted in relation to private law.

It does not appear that the government will adopt the Law Commission's recommendation that this restriction should also apply to attorneys. Making Decisions is silent on this issue in respect of the powers of attorney other than to state the fact that the consent of the attorney is to have the same authority as if it were that of the competent patient. ${ }^{43}$ If the competent patient could lawfully consent to the use of restraint then presumably so could the attorney.

The vast majority of care, nursing care and health care carried out for incompetent patients is not done with the intention of averting a substantial risk of harm, but is carried out to make them comfortable, to improve their welfare or prevent minor deterioration in their general health. Translation of the government's proposals into statutory authority may mean that certain aspects of this care, for example simple matters such as dressing and undressing; putting to bed; feeding; washing and bathing; brushing teeth, and giving medicines will not be lawful under the general authority if the assisted person objects and demonstrates that objection forcefully.

The provision of routine medical and dental care with the use of restraint may be lawful with the consent of the attorney but that is not clear. If that is not so then they are treatments which will require the prior approval of the court, or its appointed manger, if the patient, albeit an incompetent patient, strenuously objects. There seems little point in having a "best interests test" if the "best interests decision" can simply be frustrated by the resistance of a patient deemed to be incompetent and incapable of making a decision.

\section{Concluding remarks}

The common law has given legal authority for the use of restraint in caring for incompetent adult patients, although that authority still holds some uncertainties. For these patients routine care and treatment provided in good faith and in their best interests, usually following discussion with relatives and carers, and when necessary using the least restrictive or oppressive means of restraint, will be lawful. The legislative proposals contained within Making Decisions appear to suggest that such restraint may be unlawful without prior declaration from the court or its appointed manager. Such a requirement would place an intolerable burden on the legal system to the detriment of patients in need of care, not least because of the delays in receiving treatment. The law in relation to the use of restraint to enable the provision of care has developed piecemeal over the past 15 years. Consolidation of the law through statutory reform is to be welcomed. The opportunity exists for clarification of the law not only for the benefit and protection of patients but also for those responsible for their care. If there are to be changes then those changes must ensure 
that patients are able to receive care and treatment, and be cared for and be treated, easily and without complication or fear of legal repercussions.

\section{Acknowledgement}

This paper has been extracted from a dissertation submitted for the degree of MA (Healthcare Ethics and Law) at the Centre for Social Ethics and Policy, University of Manchester. The author thanks Professor Margaret Brazier for her invaluable guidance as supervisor and for her help in reading the final draft of this paper. Full responsibility for opinions expressed and any errors remain with the author.

Andrew $M$ Bridgman, BDS, LLB(Hons), $M A$, is a Clinical Teacher and Lecturer for Law and Ethics in Dentistry, Turner Dental School, University of Manchester.

\section{References}

1 Gillon R. Impaired autonomy and rejection of treatment [editorial]. Fournal of Medical Ethics 1983;9:131-2.

2 Mental Health Act 1983.

3 [1989] 2 All ER 545

4 McHale J. Law and medical ethics: mental incapacity: some

proposals for reform. Fournal of Medical Ethics. 1998;24:322-7. proposals for reform

6 See reference 3: 561

7 Re T (adult: refusal of medical treatment) [1992] 4 All ER 627 at 659.

8 Grubb A. Treatment without consent (anorexia nervosa) adult Medical Law Review. 1994; 2:95-9.

$9 S v M c C$ [1972] AC 24.

10 [[1981Z[\]z[\]Z] 2 All ER 1057.

11 [1994] 1 FLR 614.

12 See reference 11: 619

13 [1994] 19 BMLR 144 at 146.

$14 B v$ Croydon Health Authority [1994] 1 All ER 683 at 688 .
15 [1996] 1 FLR 762 at 773

16 See reference 15: 775

17 von Korff M, Simon G. The relationship between pain and depression. British fournal of Psychiatry (suppl) 1996 Jun: 101-8. Hodgkiss AD, Sufraz R, Watson JP. Psychiatric morbidity and illness behaviour in women with chronic pelvic pain. Fournal of Psychosomatic Research. 1994;8:3-9.

18 Norfolk and Norwich Healthcare (NHS) Trust $v$ W [1996] 2 FLR 613; Rochdale Healthcare (NHS) Trust v C [1997] 1 FLR 274.

19 In accordance with the principles laid down in Re F (in utero) [1988] 2 All ER 193.

20 See reference 18: 615 . phylactic, such as a sterilisation of an otherwise healthy woman, or organ donation.

22 As part of the "best interests" test. See reference 8.

23 [1997] 8 Med LR 217 at 225 .

24 See reference 3: Goff LS: 615.

25 Bolam v Friern Hospital Management Committee [1957] 2 All ER

26 Paris v Stepney Borough Council [1951] AC 367.

27 In respect of giving advice Lord Bridge in Sidaway $v$ Board of Governors of the Bethlem Royal Hospital and the Maudsley Hospital [1985] 2 WLR 480 at 505 stated that he saw no reason why the judge could not reject a conclusion arrived at by the application of the Bolam test.

28 [1997] 4 All ER 771

29 Hoggett B. Mental health law. London: Sweet and Maxwell, 1996: $140-1$.

30 Criminal Law Act section 3(1).

32 Mental incapacity. Law Com 1999.131 .1995$.

33 Who decides? Making decisions on behalf of mentally incapacitated adults. Cm 38031997.

34 See reference 31: para 1.15

35 See reference 31: para 1.16

36 See reference 31: para 1.17 .

37 See reference 3: Goff LS: 566

38 See reference 31: para 2.5

39 See reference 31: para 1.4

40 See reference 31: ch 3.

41 See reference 31 para 1.22. Note the Law Commission's original provision referred to a "substantial risk of serious harm", para 4.33 .

42 See reference 32: para 9.8.

43 See reference 31: para 2.25 